\title{
Issue of heat mirror films overheating
}

\author{
Václav Pospíšilík ${ }^{1 *}$, and Stanislav Honus ${ }^{1}$ \\ ${ }^{1}$ VSB - Technical University of Ostrava, 17. listopadu 2172/15, Ostrava-Poruba, Czech Republic
}

\begin{abstract}
The study focuses on the issue of coated thin plastic films overheating due to the absorption of solar radiation. These films are suspended within the sealed space of dual-pane insulating glass units (IGU). Films are deformed due to thermal stress and the glazing ceases to carry out its function. The surface temperature of the glazing system was evaluated from energy balance during a sunny day. It was supposed the intensity of solar radiation $1000 \mathrm{~W} / \mathrm{m} 2$. Solar radiation incidents perpendicular to the surface of the glazing. Spectroscopic measurement was performed and optical properties of glasses and films were evaluated. Finally, suitable glazing was designed, which partially prevents transmission of the solar radiation into the inner space of glazing and the thin plastic films are not significantly overheated.
\end{abstract}

\section{Introduction}

Heat mirror coating finds use in many technical fields, mainly with applications in windows [1] and solar collectors [2]. The main goal of heat mirror coating is to create ideal optical properties in terms of light transmission and at the same time prevent higher heat losses from the building than necessary. Selkowitz [3] claims that thanks to the heat mirror glazing system, it is possible to save $25-75 \%$ of energy compared to ordinary glazing. The main feature of the "heat mirror" technology is high transmittance and high reflectance in the visible region of the spectrum, low emissivity in the IR region of the spectrum, respectively.

The solar optical properties of thin metal layers applied to glass or film are very well studied. Valkonen et al. [4] analyzed the optical properties of the metal layer $(\mathrm{Cu}, \mathrm{Ag}, \mathrm{Au}$, $\mathrm{Cr}, \mathrm{Fe}, \mathrm{Co}, \mathrm{Ni}, \mathrm{Al}$ ) depending on the metal film thickness. The mentioned study showed excellent results for noble metals - $\mathrm{Cu}, \mathrm{Ag}, \mathrm{Au}$, especially. Its optical properties depending on the metal film thickness are analyzed in the paper [5]. Silver layer transmits the maximum amount of energy in the region $\lambda=500 \mathrm{~nm}$, while gold layer has a maximum at $\lambda=350 \mathrm{~nm}$, respectively. This maximum is constant and does not change with the thickness of the applied layer of material.

This study focuses on heat mirror in multiple glazing with an inner plastic sheet. This polymer film is stretched inside the glazing and divides the gas space into two. The advantage of these polymer films is their flexibility, low weight, and high impact strength [6]. The disadvantage of heat mirror films is high solar absorbance. On sunny days, these foils can significantly overheat. Subsequently, they may be permanently deformed and lose overall integrity.

\footnotetext{
*Corresponding author: vaclav.pospisilik@vsb.cz
} 
The task of this study is to determine the film surface temperature in thermodynamic equilibrium under given ambient conditions. This approach can demonstrate how heat mirror films are thermally stressed by intense sunlight. At the end of this study, several types of glazing with coated or uncoated sheets (glass, polymer film) are compared with respect to their thermal insulation and optical properties.

When solving the heat transfer by radiation between surfaces of glasses or polymer films, it is necessary to consider their wavelength-dependent optical properties. If these surfaces are optically smooth, i.e. their average length scale of surface roughness is much smaller than the wavelength of the incident electromagnetic wave, the relations from electromagnetic wave theory can be used, even for very short wavelengths [7]. For calculation surface temperature of polymer film exposed to direct solar radiation, it will be necessary to determine the amount of absorbed energy based on the relationships from geometric optics and ray tracing.

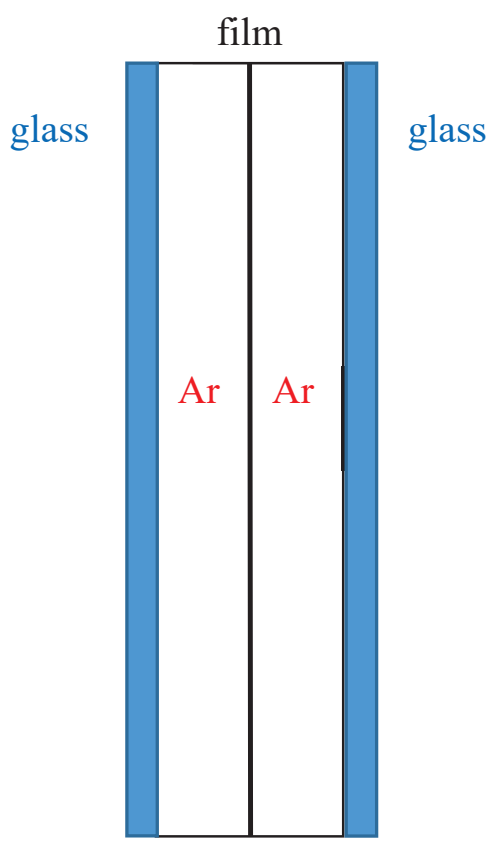

Fig. 1. Polymer film stretched inside the interglazing space, which is filled with inert gas (argon)

\section{Theory}

Glass and other amorphous solids tend to have extremely smooth surfaces, allowing for accurate predictions of optical properties from electromagnetic wave theory [7]. It is assumed that solar radiation with an intensity of $1000 \mathrm{~W} \cdot \mathrm{m}^{-2}$ incidents perpendicular to the external surface of the glazing (see FIG. 2). The incident radiation is partially reflected into the atmosphere, or passes into the interior, or is absorbed by the glazing. 


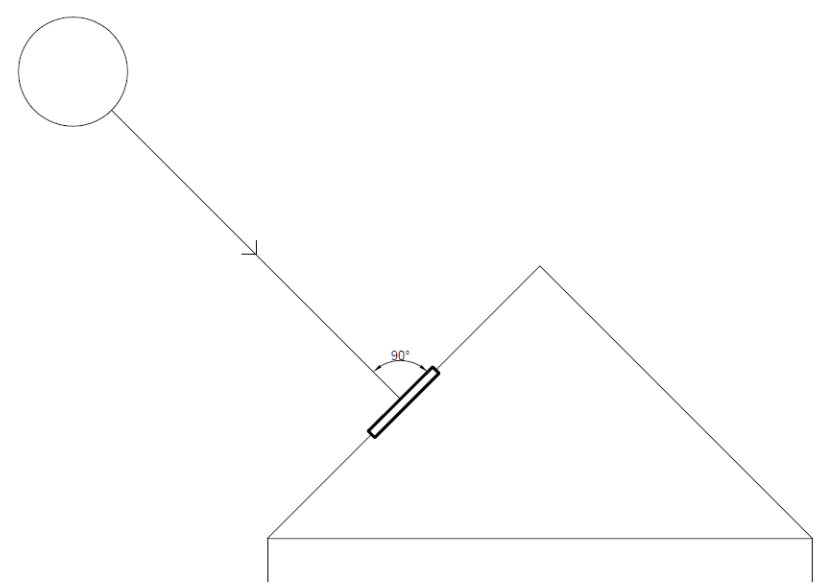

Fig. 2. Solar radiation incidents on the glazing at an angle of $90^{\circ}$

The absorbed radiation energy is determined based on the consideration of FIGURE 3. The flux reflected by the opposite glass (through the inner film) e.g., $\mathrm{T}_{\mathrm{s} 1} \mathrm{~T}_{\mathrm{sf}} \mathrm{R}_{\mathrm{s} 2} \mathrm{~T}_{\mathrm{sf}} \mathrm{A}_{\mathrm{s} 1}$ is neglected, because their value is very small. The absorbed energy of the polymer film is divided into two parts. The first of them (superscript a) is the sum of all contributions coming from the top glass. The second of them (superscript $b$ ) is the sum of the contributions coming from the lower glass.

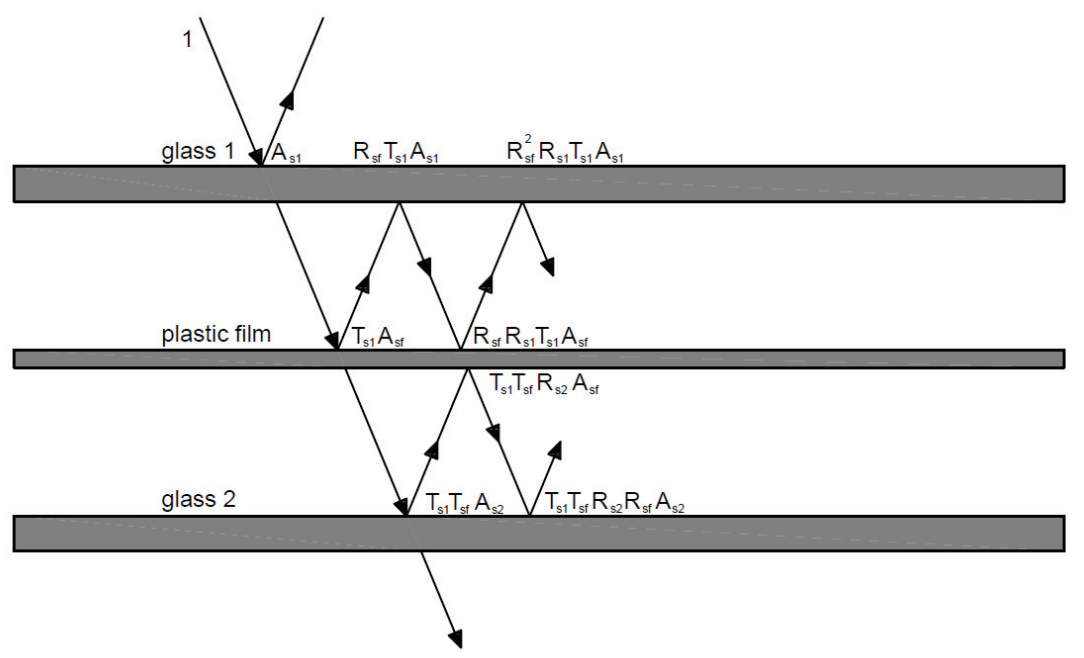

Fig. 3. Determination of absorbed energy of glass and plastic film in glazing

Spectral absorbance of glass 1:

$$
\begin{gathered}
A_{A B S, 1}=A_{S 1}+T_{s 1} \cdot R_{s f} \cdot A_{S 1}+T_{s 1} \cdot R_{s f}^{2} \cdot R_{S 1} \cdot A_{S 1}+T_{s 1} \cdot R_{s f}^{3} \cdot R_{s 1}^{2} \cdot A_{S 1}+\cdots \\
A_{A B S, 1}=A_{S 1}+T_{s 1} \cdot R_{S f} \cdot A_{S 1}\left(1+R_{s f} \cdot R_{s 1}+R_{s f}^{2} \cdot R_{s 1}^{2}+\cdots\right)
\end{gathered}
$$




$$
A_{A B S, 1, \lambda}=A_{S 1, \lambda}+\frac{T_{s 1, \lambda} \cdot R_{s f, \lambda} \cdot A_{S 1, \lambda}}{1-R_{s f, \lambda} \cdot R_{s 1, \lambda}}
$$

Spectral absorbance of film:

$$
\begin{aligned}
& A_{A B S, f, \lambda}{ }^{a}=\mathrm{T}_{s 1} \cdot A_{S f}+\mathrm{T}_{s 1} \cdot \mathrm{R}_{s f} \cdot \mathrm{R}_{s 1} \cdot A_{S f}+\mathrm{T}_{s 1} \cdot \mathrm{R}_{s f}^{2} \cdot \mathrm{R}_{s 1} \cdot A_{S f}+\cdots \\
& A_{A B S, f, \lambda}{ }^{a}=T_{s 1} \cdot A_{S f}\left(1+R_{s f} \cdot R_{s 1}+R_{s f}^{2} \cdot R_{s 1}^{2}+\cdots\right) \\
& A_{A B S, f, \lambda}{ }^{a}=\frac{T_{S 1} \cdot A_{S f}}{1-R_{S f} \cdot R_{S 1}} \\
& A_{A B S, f, \lambda}{ }^{b}=T_{S 1} \cdot T_{S f} \cdot R_{S 2} \cdot A_{S f}+T_{s 1} \cdot T_{S f} \cdot R_{s 2}^{2} \cdot R_{s f} \cdot A_{S f}+\cdots \\
& A_{A B S, f, \lambda}{ }^{b}=T_{s 1} \cdot T_{S f} \cdot R_{s 2} \cdot A_{S f}\left(1+R_{s f} \cdot R_{s 2}+R_{s f}^{2} \cdot R_{s 2}^{2}+\cdots\right) \\
& A_{A B S, f, \lambda}{ }^{b}=\frac{T_{s 1} \cdot T_{S f} \cdot R_{S 2} \cdot A_{S f}}{1-R_{S f} \cdot R_{S 2}} \\
& A_{A B S, f, \lambda}=\frac{T_{s 1, \lambda} \cdot A_{s f, \lambda}}{1-R_{s f, \lambda} \cdot R_{s 1, \lambda}}+\frac{T_{s 1, \lambda} \cdot T_{S f, \lambda} \cdot R_{s 2, \lambda} \cdot A_{s f, \lambda}}{1-R_{s f, \lambda} \cdot R_{s 2, \lambda}}
\end{aligned}
$$

Spectral absorbance of glass 2:

$$
\begin{gathered}
A_{A B S, 2, \lambda}=T_{s 1} \cdot T_{s f} \cdot A_{S 2}+T_{s 1} \cdot T_{s f} \cdot R_{s 2} \cdot R_{s f} \cdot A_{S 2}+T_{s 1} \cdot T_{s f} \cdot R_{s 2}^{2} \cdot R_{s f}^{2} \cdot A_{S 2}+\cdots \\
A_{A B S, 2, \lambda}=T_{s 1} \cdot T_{s f} \cdot A_{S 2}\left(1+R_{s f} \cdot R_{s 2}+R_{s f}^{2} \cdot R_{s 2}^{2}+\cdots\right) \\
\boldsymbol{A}_{A B S, 2, \lambda}=\frac{\boldsymbol{T}_{\boldsymbol{s 1 , \lambda}} \cdot \boldsymbol{T}_{\boldsymbol{s f}, \lambda} \cdot \boldsymbol{A}_{\boldsymbol{S} 2, \lambda}}{\mathbf{1}-\boldsymbol{R}_{\boldsymbol{s f}, \lambda} \cdot \boldsymbol{R}_{\boldsymbol{s} 2, \lambda}}
\end{gathered}
$$

Total absorbed radiative heat flux by $1 \mathrm{~m}^{2}$ glasses or plastic film is evaluated from the relation:

$$
Q_{A B S}=I \cdot \frac{\int_{250}^{2000} E_{b, \lambda} \cdot A_{A B S, \lambda} d \lambda}{\int_{250}^{2000} E_{b, \lambda} d \lambda}
$$

Where $E_{b, \lambda}$ is spectral emissive power of solar radiation at temperature of $5800 \mathrm{~K}$.

Based on the energy flows from the surface and to the surface, the equations of the total heat balance are determined. In this application, thermal distribution within the sheet is unimportant. Therefore, it is considered a constant temperature throughout the cross-section of the glass or polymer film. Heat conduction in glass or polymer film is therefore not considered. 
Glass 1:

$$
Q_{A B S, 1}-h_{\text {out }}\left(T_{1}-T_{\text {out }}\right)+\frac{k}{d}\left(T_{f}-T_{1}\right)+\frac{1}{\frac{1}{\varepsilon_{1}}+\frac{1}{\varepsilon_{f}}-1} \cdot \sigma \cdot\left(T_{f}{ }^{4}-T_{1}^{4}\right)=0
$$

Film:

Glass 2:

$$
\begin{gathered}
Q_{A B S, f}-\frac{k}{d}\left(T_{f}-T_{1}\right)-\frac{k}{d}\left(T_{f}-T_{2}\right)-\frac{1}{\frac{1}{\varepsilon_{1}}+\frac{1}{\varepsilon_{f}}-1} \cdot \sigma \cdot\left(T_{f}{ }^{4}-T_{1}{ }^{4}\right) \\
-\frac{1}{\frac{1}{\varepsilon_{2}}+\frac{1}{\varepsilon_{f}}-1} \cdot \sigma \cdot\left(T_{f}{ }^{4}-T_{1}{ }^{4}\right)=0
\end{gathered}
$$

$$
Q_{A B S, 2}-h_{\text {in }}\left(T_{1}-T_{\text {out }}\right)+\frac{k}{d}\left(T_{f}-T_{2}\right)+\frac{1}{\frac{1}{\varepsilon_{2}}+\frac{1}{\varepsilon_{f}}-1} \cdot \sigma \cdot\left(T_{f}{ }^{4}-T_{2}{ }^{4}\right)=0
$$

The term for convection in the interglazing space is not considered in the energy balance equations. It was verified by calculating the Nusselt number, whether a natural flow doesn't occur inside space. For all the glazings mentioned, a Nusselt number was equal to one.

The film, which has the highest temperature in the entire system due to the absorption of solar radiation, transfers heat by conduction surrounding the inert gas (argon) and at the same time by radiation to the inner surfaces of the glasses. The glasses are cooled mainly by external convection on both the exterior and interior sides. In table 1 are shown all considered values used in the calculation. The emissivities of the surfaces at ambient temperature were given by the manufacturer. Heat transfer coefficient in interior and exterior was determined as a recommended value according to EN 673. [8]

Table 1. Input values for the energy balance of glazing.

\begin{tabular}{|l|c|c|c|}
\hline Quantity & Symbol & Value & Unit \\
\hline Incident intensity of radiation & $\mathrm{I}$ & 1000 & $\mathrm{~W} \cdot \mathrm{m}^{2}$ \\
\hline Outside temperature & Tout & 303 & $\mathrm{~K}$ \\
\hline Inside temperature & Tin & 298 & $\mathrm{~K}$ \\
\hline Width of the gas space & $\mathrm{s}$ & 12 & $\mathrm{~mm}$ \\
\hline Thermal conductivity of gas & $\mathrm{k}$ & 0,01734 & $\mathrm{~W} \cdot \mathrm{m}^{-1} \cdot \mathrm{K}^{-1}$ \\
\hline Heat transfer coefficient in interior & hin & 7,7 & $\mathrm{~W} \cdot \mathrm{m}^{-2} \cdot \mathrm{K}^{-1}$ \\
\hline Heat transfer coefficient in exterior & hout & 25 & $\mathrm{~W} \cdot \mathrm{m}^{-2} \cdot \mathrm{K}^{-1}$ \\
\hline
\end{tabular}

\section{Spectroscopic measurement}

Spectroscopic measurement was performed on four types of glass and two types of plastic films. The following sample names are well-known trade names of commercially manufactured products. Unfortunately, due to production secrets, we do not have enough information about the composition of the deposited films on the substrate. FLO4 is an ordinary uncoated glass that has the same optical properties on both sides. A metal layer is applied to the insulating glass 6304 on one side by cathode sputtering in a vacuum. In the case of Ipasol Platin and 2504 Ultra, these are glasses with a solar reflective coating, which prevents excessive overheating of the interior of the building. Klasik is an ordinary uncoated plastic film made of PET material. On HM44 is applied a layer of silver, which reduces the emissivity of its surface.

Measurements were performed using a Cary 7000 two-beam UV-Vis-NIR spectrophotometer from Agilent. Data were measured in the wavelength range of $250 \mathrm{~nm}$ to 
$2000 \mathrm{~nm}$. This is the measuring range of this device. For the purposes of this calculation, the investigation of the optical properties of glasses and films in the narrower or longer wavelength spectrum is not essential. An Agilent Cary Universal Measurement Accessory (UMA) was used for the measurement, enabling automated measurement of reflectance and transmittance at selected angles of incidence. After measuring the background of the device (Baseline), the resulting reflectance and transmittance were obtained. Reflectance was determined as the ratio of the reflected part of incoming radiation and total incoming radiation and transmittance as the ratio of the transmitted part of incoming radiation and total incoming radiation. The minimum possible angle of incidence for measuring and determining reflectance is $6^{\circ}$. Optical properties were measured for each side of the sample for s- and ppolarization ( $\mathrm{Rs}, \mathrm{Rp}, \mathrm{Ts}, \mathrm{Tp}$ ). The resulting reflectance $\mathrm{R}$ and the transmittance $\mathrm{T}$ of unpolarized light were determined according to the relation:

$$
R=\frac{R_{s}+R_{p}}{2}, \quad T=\frac{T_{s}+T_{p}}{2}
$$

The absorbance is calculated from:

$$
A=1-R-T
$$

The spectral optical properties of glasses and plastic films are shown in Figures 4-9. Figures 4 and 6 contain a small step at around $1100 \mathrm{~nm}$. This is a systematic error of the spectrophotometer due to the rotation of the diffraction grating. This error does not significantly affect the overall calculation.



Fig. 4. Spectral reflectance of glasses 




Fig. 5. Spectral reflectance of polymer films

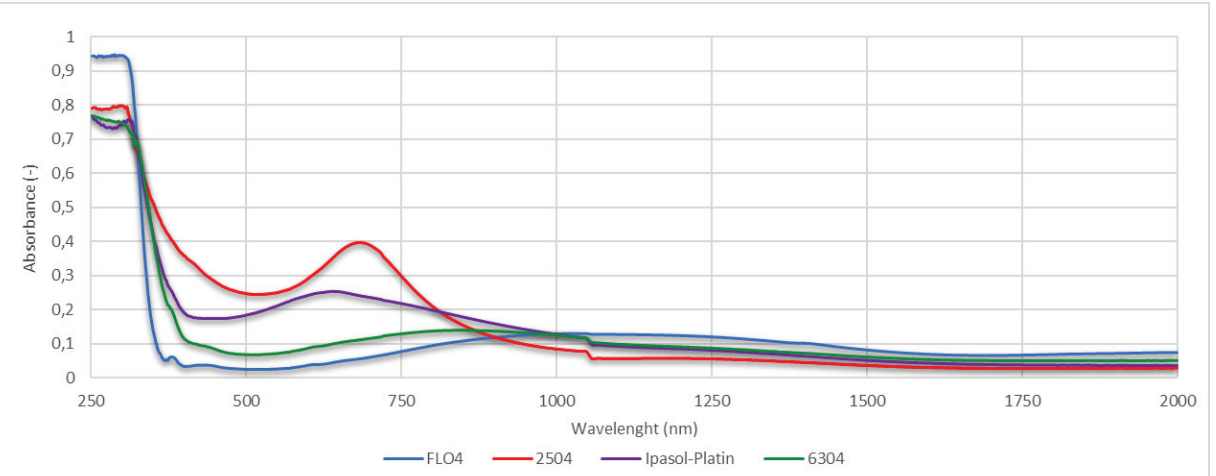

Fig. 6. Spectral absorbance of glasses

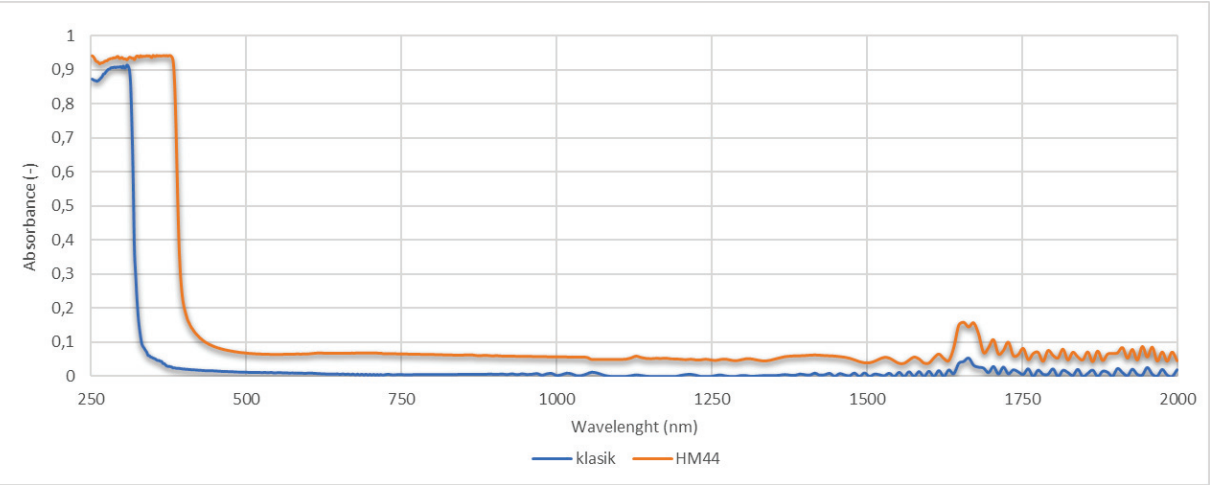

Fig. 7. Spectral absorbance of polymer films 


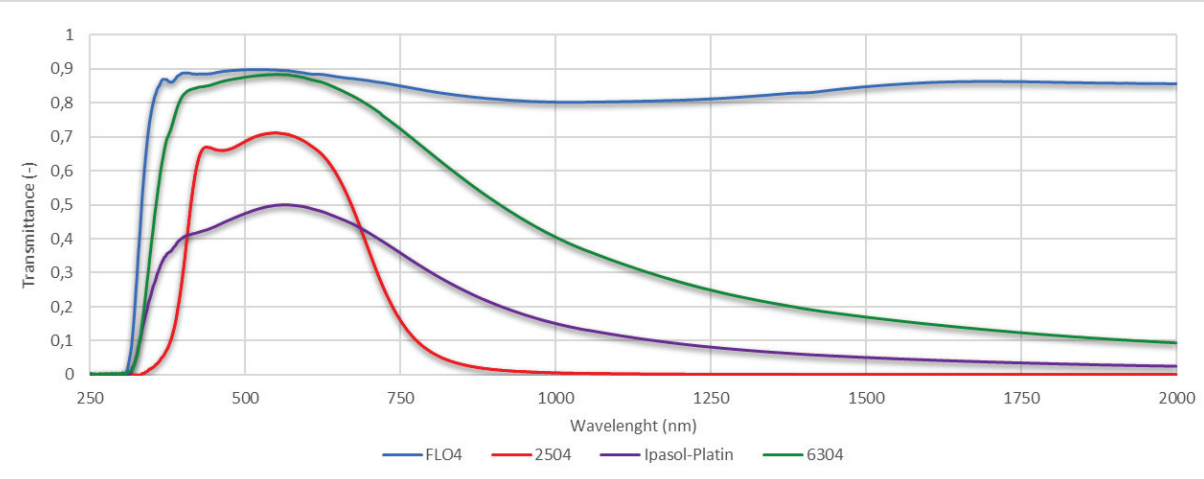

Fig. 9. Spectral transmittance of glasses

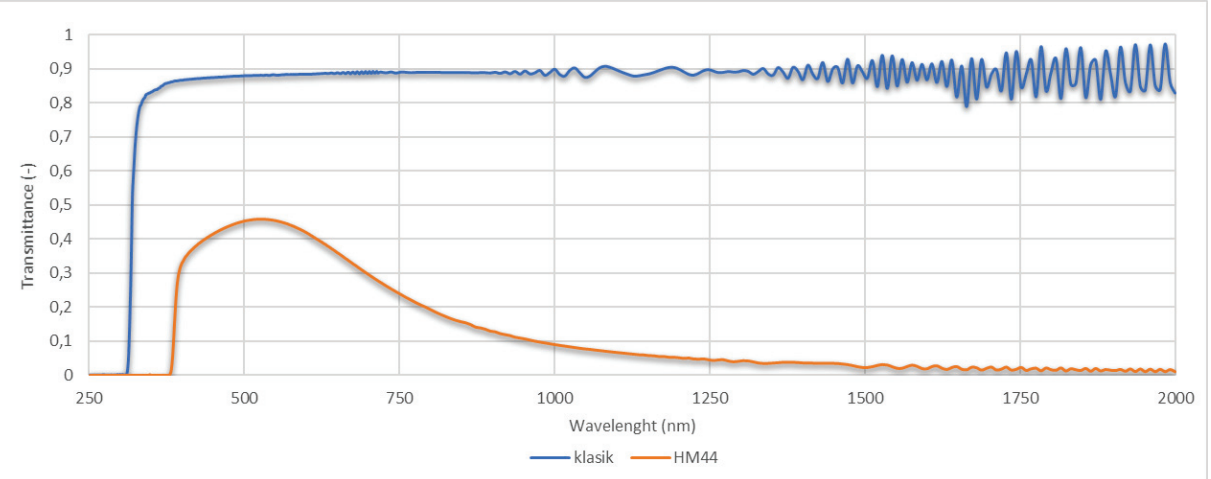

Fig. 8. Spectral transmittance of polymer films

\section{Results and discussion}

The surface temperature of coated and uncoated plastic film was calculated from the energy balance for seven types of glazing. Inner space inside glazing was filled with inert gas (argon). The considered glazings are shown in table 2.

Table 2. The surface temperature of the glass on the exterior side and surface temperature of plastic film inside the glazing

\begin{tabular}{|c|c|c|}
\hline Glazing number & $\begin{array}{c}\text { Glass } \\
\text { temperature } t_{1} \\
\left({ }^{\circ} \mathrm{C}\right)\end{array}$ & $\begin{array}{c}\text { Film } \\
\text { temperature } \mathbf{t}_{\mathrm{f}} \\
\left({ }^{\circ} \mathrm{C}\right)\end{array}$ \\
\hline FLO4 - $12 \mathrm{~mm} \mathrm{Ar}-$ klasik - $12 \mathrm{~mm} \mathrm{Ar}-\mathrm{FLO} 4$ & 35 & 35,1 \\
\hline FLO4-12 mm Ar-HM 44-12 mm Ar-FLO4 & 39 & 75,8 \\
\hline $6304-12 \mathrm{~mm} \mathrm{Ar}-\mathrm{HM} 44-12 \mathrm{~mm} \mathrm{Ar}-6304$ & 40,2 & 68 \\
\hline Ipasol Platin - $12 \mathrm{~mm} \mathrm{Ar}$ - klasik - $12 \mathrm{~mm} \mathrm{Ar}-\mathrm{FLO} 4$ & 39,3 & 31,8 \\
\hline 2504 Ultra- $12 \mathrm{~mm} \mathrm{Ar}$ - klasik - $12 \mathrm{~mm} \mathrm{Ar}-\mathrm{FLO} 4$ & 41,4 & 31,2 \\
\hline Ipasol Platin - $12 \mathrm{~mm} \mathrm{Ar}-\mathrm{HM} 44-12 \mathrm{~mm} \mathrm{Ar}-\mathrm{FLO} 4$ & 39,9 & 41,3 \\
\hline 2504 Ultra- $12 \mathrm{~mm} \mathrm{Ar}-\mathrm{HM} 44-12 \mathrm{~mm} \mathrm{Ar}-\mathrm{FLO} 4$ & 41,7 & 36 \\
\hline
\end{tabular}




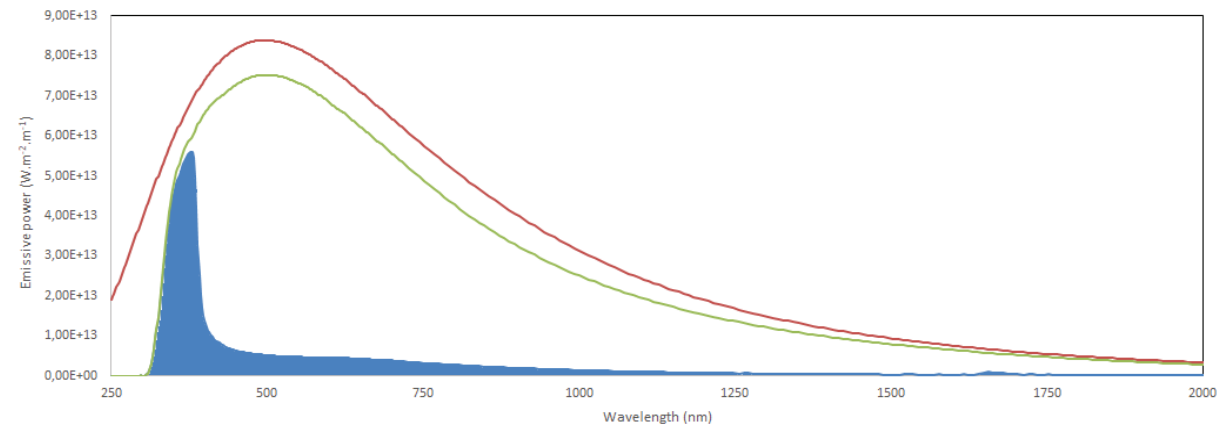

Fig. 11. Radiative heat flux absorbed by HM44 - blue area

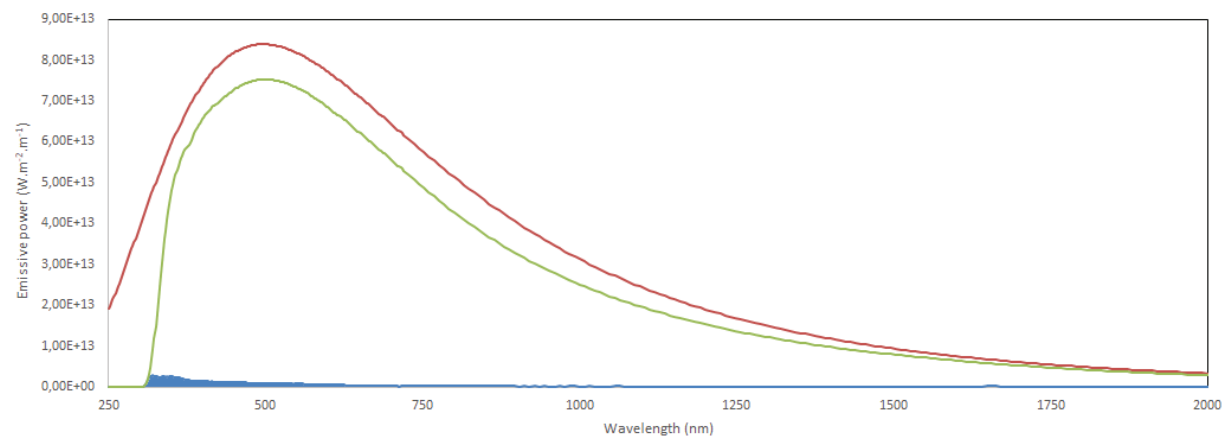

Fig. 10. Radiative heat flux absorbed by uncoated film klasik - blue area

Table 2 also shows the results of the surface temperatures of coated and uncoated glasses or films in the glazing. These glasses are the first "barrier" against the effects of solar radiation. The higher reflectance of the first glass in the UV-Visible-NIR region, the less solar radiation will be transmitted to the plastic film.

From table 2 can be seen that HM44 is exposed to significant thermal stress due to solar radiation. The triple glazing with two outer uncoated glasses and one inner film HM 44 can be heated to very high temperatures (over $75^{\circ} \mathrm{C}$ ). Polymer films are overheating due to poor heat dissipation from the interglazing space. The polymer film is surrounded by an inert gas with low thermal conductivity. In addition, it is desirable that gas surrounding the film doesn't flow, thus achieving the lowest possible U-value. Plastic film transfers heat mainly by radiation to the surrounding walls. More intensive heat transfer by radiation to the surrounding walls is prevented by low emissivity in the IR region. Using coated glass (2504Ultra, Ipasol Platin) on the exterior side, which reflects part of the solar radiation to the outdoor environment, the intensity of radiation transmitted inside the glazing space is significantly reduced. Consequently, the HM 44 absorbs less energy and there is no intense overheating. This surface temperature poses a much lower risk of deforming the stretched film inside the interglazed space.

Figures 10 and 11 show the ratio between the total amount of energy incidents on the glazing - area under the red line (blackbody at temperature $5800 \mathrm{~K}$ ), the transmitted thermal radiation through the first glass - area under the green line, and finally, the total absorbed energy of the coated or uncoated polymer film - area under blue line. It should be noted that the attenuation of solar radiation by the atmosphere is included in the calculation by the value of incident intensity of radiation $1000 \mathrm{~W} / \mathrm{m}^{2}$. The figures show that absorbed energy by HM44 film is many times greater than uncoated film klasik. 
The combination of glasses with solar-reflective surfaces and uncoated film klasik has no significant effect on the thermal stress of the film. There is almost no thermal deformation and therefore is often used in multi-glazing. However, uncoated surface has greater emissivity in the IR region, i.e., higher heat losses through the overall glazing. Table 3 shows the calculated U-value (thermal transmittance of the glazing) according to the EN 673 [8] of all triple glazing considered above. Glazing with interglazed film klasik has U-value of 1 and 1,7 in contrast to glazing with HM 44, where the U-value is 1 and 0.7 .

Table 3. U-value for several types of glazing

\begin{tabular}{|c|c|}
\hline Glazing number & U-value \\
\hline FLO4-12 mm Ar - klasik - $12 \mathrm{~mm} \mathrm{Ar-FLO4}$ & 1,7 \\
\hline FLO4-12 mm Ar- $\mathrm{HM} 44-12 \mathrm{~mm} \mathrm{Ar}-\mathrm{FLO} 4$ & 1 \\
\hline $6304-12 \mathrm{~mm} \mathrm{Ar}-\mathrm{HM} 44-12 \mathrm{~mm} \mathrm{Ar}-6304$ & 0,7 \\
\hline Ipasol Platin - $12 \mathrm{~mm} \mathrm{Ar}$ - klasik - $12 \mathrm{~mm} \mathrm{Ar-FLO4}$ & 1 \\
\hline 2504 Ultra- 12 mm Ar - klasik - 12 mm Ar - FLO4 & 1 \\
\hline Ipasol Platin - $12 \mathrm{~mm} \mathrm{Ar}$ - HM $44-12$ mm Ar - FLO4 & 0,7 \\
\hline 2504 Ultra- $12 \mathrm{~mm} \mathrm{Ar}-\mathrm{HM} 44-12 \mathrm{~mm} \mathrm{Ar}-\mathrm{FLO} 4$ & 0,7 \\
\hline
\end{tabular}

\section{Conclusion}

Based on the calculation of the energy balance of the sun - glazing - the surrounding environment, it was proved that there is significant overheating of coated heat mirror films located inside the interglazed space. These Heat Mirror films can be heated to very high temperatures (over $75^{\circ} \mathrm{C}$ ). Due to thermal expansion, the stretched film may deform, and the glazing may become unusable. It has been shown that the use of a suitable coated glass which is able to absorb or reflect a large part of the thermal radiation in short wavelengths significantly reduces the thermal loading of the films.

This study was supported by the student project No. SP2021/110 and also by doctoral grant system (CZ.02.2.69/0.0./0.0/19_073/0016945, Project DGS/TEAM/2020-030).

\section{References}

1. M. Rubin, R. Creswick a S. Selkowitz, „Transparent Heat Mirrors for Windows: thermal performance," $v 5$ th National Passive Solar Conference, Amherst, 1980. M. P. Brown and K. Austin, Appl. Phys. Letters 85, 2503-2504 (2004).

2. S. Yoshida, „Efficiency of Drude mirror-type selective transparent filters for solar thermal conversion,“ Appl. Opt. 17, pp. 145-150, 1978.

3. S. Selkowitz, „Transparent heat mirrors for passive solar heating applications, “ v 2nd National Passive Solar, Philadelphia, 1978.

4. E. Valkonen, B. Karlsson a C.-G. Ribbing, „Solar Optical Properties of Thin Films of $\mathrm{Cu}, \mathrm{Ag}, \mathrm{Au}, \mathrm{Cr}, \mathrm{Fe}, \mathrm{Co}, \mathrm{Ni}$ and Al,“ Solar Energy, pp. 211-222, 1983.

5. A. Axelevitch, B. Gorenstein a G. Golan, „Investigation of Optical Transmission in Thin Metal Films, “ Physics Procedia 32, pp. 1-13, 2012.

6. A. Solovyev, S. Rabotkin a N. Kovsharov, „Polymer films with multilayer low-E coatings, “" Materials Science in Semiconductor Processing 38, pp. 373-380, 2015.

7. F. M. Modest, Radiative Heat Transfer, Boston: Academic Press, 2003.

8. DE NORMALISATION, ComitéEuropéen. EN 673: 2011, Glass in building. Determination of thermal transmittance (U value). Calculation method, 2011. 